\title{
Inhibition of CYP1B1 ameliorates cardiac hypertrophy induced by uremic toxin
}

\author{
YING ZHANG ${ }^{*}$, SHAOBO WANG* , YINGHUI HUANG, KE YANG, YONG LIU, XIANJIN BI, \\ CHI LIU, JIACHUAN XIONG, BO ZHANG, JINGHONG ZHAO and LING NIE
}

\begin{abstract}
Department of Nephrology, The Key Laboratory for The Prevention and Treatment of Chronic Kidney Disease of Chongqing, Kidney Center of PLA, Xinqiao Hospital, Army Medical University

(Third Military Medical University), Chongqing 400037, P.R. China
\end{abstract}

Received April 10, 2019; Accepted October 7, 2019

DOI: $10.3892 / \mathrm{mmr} .2019 .10810$

\begin{abstract}
Cardiovascular disease is the predominant complication and leading cause of mortality in patients with chronic kidney disease (CKD). Previous studies have revealed that uremic toxins, including indoxyl sulfate (IS), participate in cardiac hypertrophy. As a heme-thiolate monooxygenase, cytochrome P450 family 1 subfamily B member 1 (CYP1B1) is able to metabolize arachidonic acid into hydroxyeicosatetraenoic acids, which are thought to serve a central function in the pathophysiology of the cardiovascular system. However, whether CYP1B1 is involved in cardiac hypertrophy induced by uremic toxins remains unknown. The present study revealed that the expression of the CYP1B1 gene was significantly $(\mathrm{P}<0.05, \mathrm{CKD}$ or IS vs. control) upregulated by CKD serum or IS at the transcriptional and translational level. Furthermore, IS treatment resulted in the nuclear translocation of aryl hydrocarbon receptor (AhR), an endogenous ligand of IS. Binding of $\mathrm{AhR}$ in the promoter region of CYP1B1 was confirmed using a chromatin immunoprecipitation assay in the cardiomyoblast $\mathrm{H} 9 \mathrm{c} 2$ cell line. In addition, knockdown of AhR or CYP1B1 reversed the production of cardiac hypertrophy markers. The in vivo injection of a CYP1B1 inhibitor significantly $(\mathrm{P}<0.05$, Inhibitor vs. control) attenuated cardiac hypertrophy in mice. The data from the present study clearly demonstrated that CYP1B1 was involved in cardiac hypertrophy induced by uremic toxins.
\end{abstract}

Correspondence to: Dr Ling Nie, Department of Nephrology, The Key Laboratory for The Prevention and Treatment of Chronic Kidney Disease of Chongqing, Kidney Center of PLA, Xinqiao Hospital, Army Medical University (Third Military Medical University), 83 Xinqiao Street, Chongqing 400037, P.R. China

E-mail: ricknie@tmmu.edu.cn

*Contributed equally

Key words: cytochrome P450 family 1 subfamily B member 1, cardiac hypertrophy, indoxyl sulfate, chronic kidney disease, aryl hydrocarbon receptor

\section{Introduction}

Cardiovascular disease (CVD) is the predominant complication in patients with chronic kidney disease (CKD), and is also the leading cause of mortality among patients with end stage renal failure (1-3). Left ventricular hypertrophy (LVH) is a typical pathological feature of cardiovascular lesions observed in these patients, which was previously thought to be caused by long-term hypertension and volume overload. However, even when controlling blood pressure and volume load, LVH still exists (4), suggesting that other pro-hypertrophy factors must be present.

There is a large body of evidence to suggest that the uremic milieu itself serves a critical function in the development and progression of CVD (5). Although CVD prevalence and mortality rates may vary amongst different studies, the prevalence of CVD is estimated to be between 14.4-34.0\% across a range of different ethnic groups $(6,7)$. One previous study has revealed that indoxyl sulfate (IS), a typical protein-bound uremic toxin that is produced by intestinal bacteria and accumulates in the blood with the progression of CKD, participates in cardiac hypertrophy (8). Another previous study has suggested that the serum levels of IS were independently associated with LVH, and IS-induced cardiomyocyte hypertrophy was observed in vitro, and was further confirmed by the intraperitoneal injection of IS in mice (9). In addition, it has also been demonstrated that IS may induce reactive oxygen species (ROS) production by inhibiting the protein kinase AMP-activated catalytic subunit $\alpha 2$ (AMPK)/uncoupling protein 2 (UCP2) signaling pathway (10). However, the ROS production induced by IS cannot be completely reversed by an AMPK activator. This suggests that another signaling pathway may also be involved in its biological functions. On the other hand, oral charcoal adsorbents that are able to lower serum IS levels were reported to prevent the progression of cardiac hypertrophy in CKD $(11,12)$. These studies reveal the deleterious vascular effects of IS under uremic conditions.

Previously, IS was demonstrated to be a potent endogenous agonist of the aryl hydrocarbon receptor (AhR), which is a ligand-activated helix-loop-helix transcription factor involved in the regulation of biological responses to planar aromatic hydrocarbons $(13,14)$. Prior to ligand binding, AhR is 
sequestered in the cytoplasm; following activation by ligands, AhR is translocated into the nucleus where it complexes with the AhR nuclear translocator (ARNT), and binds to a specific DNA promoter sequence including the DNA replication-related element (DRE) or the xenobiotic responsive element (XRE), and modulates the subsequent transcription of its downstream target genes, including xenobiotic-metabolizing enzymes (15). It is generally accepted that induction of cytochrome P450 family 1 subfamily A member 1, cytochrome P450 family 1 subfamily A member 2 and cytochrome $\mathrm{P} 450$ family 1 subfamily B member 1 (CYP1B1) is considered cardiotoxic through generating ROS and endogenous arachidonic acid (AA) metabolites (16). Among these targets, CYP1B1 has an important function in CVD.

CYP1B1, a heme-thiolate monooxygenase that catalyzes numerous reactions involved in drug metabolism and synthesis of cholesterol, steroids and other lipids, is able to metabolize AA into hydroxyeicosatetraenoic acids (HETEs), which are thought to serve a central function in the pathophysiology of the cardiovascular system (17). CYP1B1 was reported to mediate angiotensin (Ang) II-induced vascular smooth muscle cell migration, proliferation and hypertrophy (18). In a rat model of isoprenaline-induced cardiac hypertrophy, expression of the CYP1B1 gene was substantially increased during pressure overloads (19). Furthermore, the selective inhibition of CYP1B1 with 2,4,3',5'-tetramethoxystilbene (TMS) protected against Ang II or isoproterenol induced cardiac hypertrophy $(20,21)$. Overall, these results suggest that CYP1B1 is associated with cardiac hypertrophy.

However, whether CYP1B1 is involved in cardiac hypertrophy induced by uremic toxins remains unknown. Gondouin et al (22) revealed that IS is able to induce the upregulation of CYP1B1 in endothelial cells. Therefore, the present study hypothesized that IS may also possess the same function in cardiomyocytes. In order to investigate this theory, rat embryonic cardiomyoblast $\mathrm{H} 9 \mathrm{c} 2$ cells were treated with various doses of IS or uremic toxin in the present study, and the gene expression of CYP1B1 was detected. The data demonstrated that CYP1B1 was involved in cardiac hypertrophy induced by uremic toxins, while suppression of CYP1B1 ameliorated cardiac hypertrophy.

\section{Materials and methods}

Materials. IS was purchased from Sigma-Aldrich (Merck KGaA, Darmstadt, Germany). Primary antibodies against CYP1B1 (cat no. ab185954) and AhR (cat no. ab2769) were obtained from Abcam (Cambridge, MA, USA). The antibodies anti-Histone H3 (cat no. 4499) and anti- $\beta$-actin (cat no. 3700) were obtained from Cell Signaling Technology, Inc. Small interfering RNA (siRNA) of CYP1B1 and AhR were obtained from Shanghai GenePharma Co., Ltd. and the sequences of these siRNA are presented in Table SI. Transfection reagent Lipofectamine ${ }^{\circledR} 2000$ was obtained from Invitrogen (Thermo Fisher Scientific, Inc.). The chromatin immunoprecipitation (ChIP) kit EZ-ChIP was obtained from EMD Millipore. All primers were synthesized by Shanghai Sangong Pharmaceutical Co., Ltd.

Human serum. A total of 15 patients with primary CKD at stage $\mathrm{V}$ (age range 55-64 years, mean age 59.4, 8 male and 7 female, Chinese and ethnically Han, and 15 sex- and age-matched controls were enrolled from the Department of Nephrology of Xinqiao Hospital (Chongqing, China) between July and October 2018. The protocol of the present study was ethically approved by the Ethics Committee of Xinqiao Hospital (approval no. 2018-006-01), and was performed in accordance with the Declaration of Helsinki. All patients and healthy controls provided written informed consent as a form provided by the Ethical Committee of Xinqiao Hospital (Third Military Medical University) prior to the start of the study to confirm the collection and use of the samples in the present study.

Animals. Male C57BL/6J mice were obtained from Beijing HFK Bioscience Co., Ltd. Mice $(n=18)$ at 8 weeks of age were housed under controlled temperature $\left(25^{\circ} \mathrm{C}\right)$, humidity (50-70\%) and 12-h light/dark cycle with free access to food and water. Mice were divided into 3 groups. The first group $(n=6)$ received dimethyl sulfoxide (DMSO; 50\% in saline, v/v) intraperitoneally. The second group $(n=6)$ was treated with a single daily dose of $100 \mathrm{mg} / \mathrm{kg}$ IS for 8 weeks intraperitoneally. The third group $(\mathrm{n}=6)$ was administered $300 \mu \mathrm{g} / \mathrm{kg}$ TMS (MedChemExpress LLC) in DMSO every third day plus a daily dose of $100 \mathrm{mg} / \mathrm{kg}$ IS for 8 weeks intraperitoneally. Subsequently, the mice were euthanized by cervical dislocation under isoflurane (2\%)-inhaled anesthesia $24 \mathrm{~h}$ following the final injection. Hearts were immediately frozen in liquid nitrogen and stored at $-80^{\circ} \mathrm{C}$. The parameters of heart function were monitored by micro-computed tomography. All animal studies were ethically approved by the Institutional Animal Care and Use Committee of Third Military Medical University, and were performed in accordance with the animal care guidelines of Third Military Medical University.

Cell culture and treatment. Rat embryonic cardiomyoblast $\mathrm{H} 9 \mathrm{c} 2$ cell line was purchased from Shanghai Cell Bank (http://www.cellbank.org.cn). Cells were cultured in Dulbecco's modified Eagle's medium with $10 \%$ fetal bovine serum, at $37^{\circ} \mathrm{C}$ in a humidified incubator containing $5 \% \mathrm{CO}_{2}$. For the IS treatment, increasing concentrations of IS $(0,0.1$, 0.25 and $0.5 \mathrm{mM}$ ) were added to the medium. Cells were treated with IS for the indicated periods ( $0,24,48$ and $72 \mathrm{~h}$ ). For treatment with human serum, individual serum samples were diluted at room temperature with the complete culture media $(1: 4, v / v)$, and the cells were treated with diluted serum for $48 \mathrm{~h}$.

Reverse transcription-quantitative PCR (RT-qPCR). Total RNA was isolated from the cell culture and heart tissues using TRIzol ${ }^{\circledR}$ (Invitrogen; Thermo Fisher Scientific, Inc.). The RNA was reverse transcribed into cDNA and RT-qPCR was performed as previously described (9). Briefly, a reaction volume of $10 \mu \mathrm{l}$ containing primers $(1.0 \mu \mathrm{M})$, cDNA (100 ng) and 1XPCR mixture with SYBR I Green (Takara Biotechnology Co., Ltd.) was amplified on an iCycler iQ (Bio-Rad Laboratories, Inc.), with the thermocycling conditions of one cycle of $95^{\circ} \mathrm{C}$ for $5 \mathrm{~min}, 36$ cycles of $95^{\circ} \mathrm{C}$ for $30 \mathrm{sec}, 60^{\circ} \mathrm{C}$ for $30 \mathrm{sec}$ and $72^{\circ} \mathrm{C}$ for $60 \mathrm{sec}$, then one cycle of $72^{\circ} \mathrm{C}$ for $5 \mathrm{~min}$. Expression levels of CYP1B1, AhR, atrial natriuretic factor (ANF), brain natriuretic peptide (BNP) and $\beta$-myosin heavy chain ( $\beta$-MHC) were calculated relative to 
GAPDH expression, using the $2^{-\Delta \Delta \mathrm{Cq}}$ method (23). All primers are listed in Table SII.

Western blot analysis. Protein samples were prepared from the cell culture (H9c2, 1x106) and heart tissues using RIPA buffer containing protease inhibitors (Beyotime Institute of Biotechnology, Haimen, China). Protein expression levels were measured by assessing band thickness in the gel-phase of the western blot analysis as previously described (9). The following antibodies were used for the western blot analysis: Anti-CYP1B1 (1:1,000), anti-AhR (1:1,000), anti-Histone H3 $(1: 1,000)$ and anti- $\beta$-Actin $(1: 1,000)$. The blots were then incubated with the corresponding secondary antibodies $(1: 2,000)$ conjugated with horseradish peroxidase (cat nos. ZDR-5306 or ZDR-5307, OriGene Technologies, Inc.). The immunoreactive proteins were detected using a ECL Detection System (Thermo Fisher Scientific, Inc.). Finally, the membranes were scanned and the densitometry analysis was performed using an image analysis system (Image Lab, v.3.0; Bio-Rad Laboratories Inc.). To validate the data, the western blot analysis was repeated at least 3 times.

Immunofluorescence assay. The immunofluorescence assay was performed on $\mathrm{H} 9 \mathrm{c} 2$ cells $\left(2 \times 10^{5}\right)$ fixed in $4 \%$ paraformaldehyde for $15 \mathrm{~min}$ at room temperature as previously described (9). The following antibodies were used: Anti-AhR (1:100) and anti- $\alpha$-actinin (1:200, ab137346; Abcam). The nucleus was labeled with $1 \mathrm{mg} / \mathrm{ml}$ 4',6-Diamidino-2-phenylindole, dihydrochloride in phosphate buffered saline (PBS; Roche Diagnostics) for $5 \mathrm{~min}$ at room temperature. Images were captured using a Leica TCS-SP5 laser-scanning confocal microscope (magnification, x400; Leica Microsystems, Inc.).

Heart histology. The hearts were fixed in buffered formalin for $24 \mathrm{~h}$ at room temperature and dehydrated with increasing concentrations of ethanol $(70,80,95$ and $100 \%$ for $2 \mathrm{~h}$, respectively) and subsequently with xylene (30 min, 3 times). Finally, the hearts were embedded in paraffin. The embedded tissues were cut into $3 \mu \mathrm{m}$ sections and were processed with xylene (10 min, twice) and rehydrated with decreasing concentrations of ethanol (100, 95, 90, 80 and $70 \%$ for $5 \mathrm{~min}$, respectively). Then the sections were stained with hematoxylin-eosin (HE) with a commercial kit (C0105, Beyotime Institute of Biotechnology) in accordance with the manufacturer's protocol and were observed under a light microscope (magnification, x200, Olympus CX22; Olympus Corporation).

Immunohistochemistry assay. The paraffin sections (3 $\mu \mathrm{m})$ of the hearts were analyzed via immunohistochemistry using antibodies against CYP1B1 or AhR using standard methods. Following rehydration, nonenzymatic antigen retrieval was performed by heating the sections to $95-100^{\circ} \mathrm{C}$ in citrate buffer (10 mM, pH 6.0) for $15 \mathrm{~min}$ and washed three times with phosphate buffered saline (PBS) for $5 \mathrm{~min}$. The sections were immersed in $3 \%(\mathrm{v} / \mathrm{v}) \mathrm{H}_{2} \mathrm{O}_{2}$ for 5 min and washed three times with PBS for 5 min prior to using QuickBlock Blocking Buffer (P0231, Beyotime Institute of Biotechnology) for $10 \mathrm{~min}$. Following incubation with primary antibodies (CYP1B1 or $\mathrm{AhR}, 1: 100)$ at $4^{\circ} \mathrm{C}$ overnight, the slides were then incubated with enzyme-conjugated secondary antibodies (PV9001 or
PV9002, 1:200, OriGene Technologies, Inc.) and visualized using 3,3'-diaminobenzidine. Slides were then observed using an inverted microscope (magnification, x400, Olympus BX63; Olympus Corporation). The negative controls used PBS in place of the primary antibody. Images were randomly captured using the microscope.

ChIP analysis. ChIP was performed using a commercial EZ-ChIP kit as previously described (24). Briefly, IS-treated $\mathrm{H} 9 \mathrm{c} 2$ cells or normal controls $\left(1 \times 10^{7}\right)$ were harvested and washed in cold PBS. Cells were then immediately fixed in $1 \%$ formaldehyde for $10 \mathrm{~min}$ at room temperature and halted using $0.125 \mathrm{M}$ glycine. Cell lysates were sonicated, and the sheared cross-linked chromatin was immunoprecipitated with antibodies against CYP1B1 (target), histone $\mathrm{H} 3$ (positive control) or normal immunoglobulin G (IgG; negative control) overnight. Chromatin was then collected, washed and decross-linked at $65^{\circ} \mathrm{C}$. DNA was purified using spin columns and detected with regular and quantitative PCR. Primers are listed in Table SIII.

Knockdown of CYPIB1 and AhR in H9c2 cells. H9c2 cells $\left(2 \times 10^{4}\right)$ in 6 -well plate were transfected with $50 \mu \mathrm{M}$ of siRNA against CYP1B1 or AhR or negative control siRNA using Lipofectamine ${ }^{\circledR} 2,000$ according to the manufacturer's protocol. After incubating with siRNA for $4 \mathrm{~h}$, the media were refreshed. Following 2 days, the efficiency of the knockdown of the target was evaluated by analyzing the protein level of CYP1B1 or AhR. In order to analyze the biological functions of the knockdown, H9c2 cells were further treated with IS as aforementioned.

Statistical analysis. All data are expressed as the mean \pm standard error of the mean. Unpaired, two-tailed $\mathrm{t}$-tests and one-way analysis of variance followed by Tukey's multiple comparison test were used. The statistical analysis was performed using SPSS software (version 13.0; SPSS, Inc., Chicago, IL, USA). $\mathrm{P}<0.05$ was considered to indicate a statistically significant result.

\section{Results}

Induction of CYPIBI by CKD serum and IS in H9c2 cells. $\mathrm{H} 9 \mathrm{c} 2$ cells were treated with serum from patients with CKD in the present study. The effect of the serum on cardiac hypertrophy markers, including ANF, BNP and $\beta$-MHC, was detected using RT-qPCR. As presented in Fig. 1A, all these markers were significantly induced by CKD serum when compared with that of the healthy controls $(\mathrm{P}<0.01)$. The protein levels of CYP1B1 were then detected via western blot analysis, and the results revealed that the CYP1B1 protein was substantially upregulated by CKD serum compared with the control (Fig. 1B). In order to further determine whether the induction of CYP1B1 was at the translational or transcriptional level, the mRNA level of CYP1B1 was detected via RT-PCR. As presented in Fig. 1C, the CYP1B1 mRNA levels in H9c2 cells treated with CKD serum were significantly increased compared with the controls $(\mathrm{P}<0.01)$.

IS is the most abundant uremic toxin in CKD serum. The present study further investigated its effect on gene expression of CYP1B1. As the IS concentration in patients with CKD 
A

B

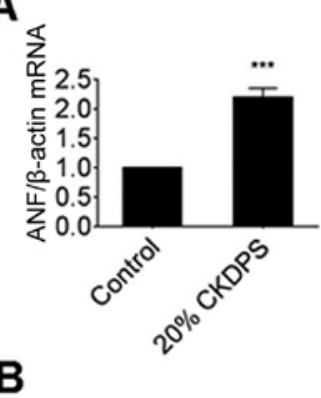
CYP1B1 $\beta$-actin

D

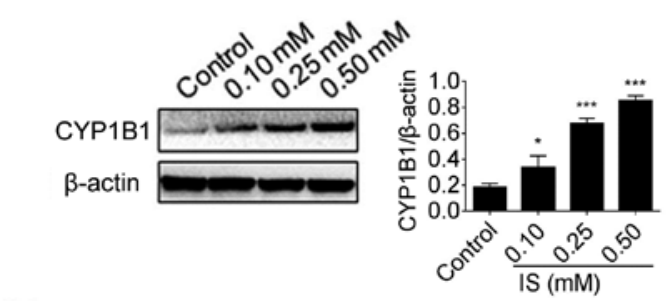

$\mathbf{F}$

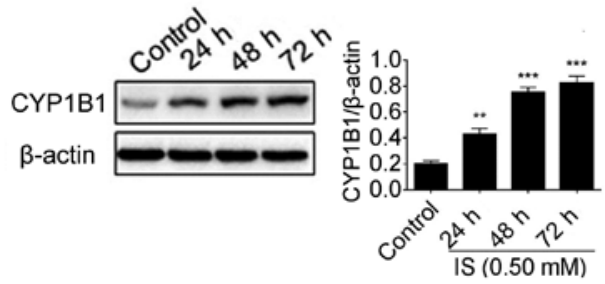

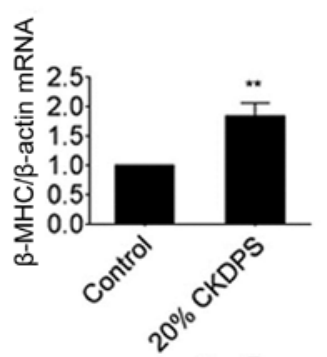

C

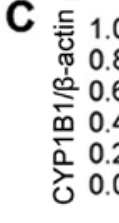

E

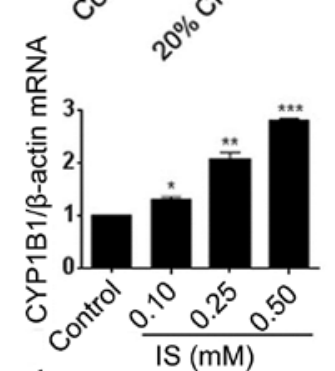

G

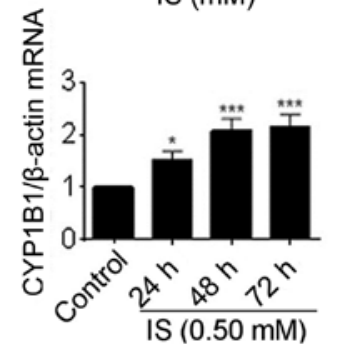

Figure 1. CYP1B1 expression was induced by CKD serum or IS in H9c2 cells. Rat embryonic cardiomyoblast H9c2 cells were treated with serum from patients with CKD or healthy controls. (A) Total RNAs were isolated for RT-PCR in order to analyze the gene expression of cardiac hypertrophy markers. (B) Protein samples were detected using western blot analysis with antibodies against CYP1B1. H9c2 cells were treated with increasing concentrations of IS for 2 days or with $500 \mu \mathrm{M}$ IS for the indicated periods of time. (C) Total RNAs were isolated for RT-PCR in order to analyze the gene expression of CYP1B1. Total protein levels of CYP1B1 were detected via western blot analysis for (D) increasing concentrations of IS and (F) increasing durations of treatment, and total RNA levels of CYP1B1 were determined using RT-PCR for (E) increasing concentrations of IS and (G) increasing durations of treatment. "P<0.05, ${ }^{* *} \mathrm{P}<0.01$ and ${ }^{* * *} \mathrm{P}<0.001$ vs. the control group. CKD, chronic kidney disease; IS, indoxyl sulfate; RT-PCR, reverse transcription-polymerase chain reaction; CYP1B1, cytochrome P450 family 1 subfamily B member 1; ANF, atrial natriuretic factor; BNP, brain natriuretic peptide; $\beta$-MHC, $\beta$-myosin heavy chain.

was reported to vary from 7.6-656.0 $\mu \mathrm{M}$ (25), $500 \mu \mathrm{M}$ IS was selected as the maximal dose in the present study. Consistent with previous results, all markers of myocardial hypertrophy were significantly increased at an IS concentration of 0.25 or $0.50 \mathrm{mM}$ compared with the control $(\mathrm{P}<0.05)$, as determined by RT-PCR (Fig. S1A-B). In order to assess whether IS may induce the gene expression of CYP1B1, H9c2 cells were also treated with an increasing dose of IS. The results from the present study revealed that the protein levels of CYP1B1 were significantly upregulated by IS in a dose- and time-dependent manner $(\mathrm{P}<0.05$; Fig. $1 \mathrm{D}$ and $\mathrm{E})$. In addition, the mRNA levels of CYP1B1 were detected using RT-PCR. As presented in Fig. $1 \mathrm{~F}$ and $\mathrm{G}$, the CYP1B1 mRNA levels in IS-treated H9c2 cells were significantly increased compared with the control $(\mathrm{P}<0.05)$, while also revealing a similar doseand time-dependent manner. These data indicated that the gene expression of CYP1B1 in H9c2 cells was induced by the uremic toxin.
Gene expression of CYPIBI in CKD or IS-treated mice. In order to further investigate the effect of the uremic toxin on the gene expression of CYP1B1 in vivo, two mouse models were applied. As the IS concentration in CKD mice has previously been reported to be increased (26), a CKD model was established by $5 / 6$ electrocoagulation and was applied in the present study. The other model was established by direct intraperitoneal injections of IS. The pathological changes of myocardial hypertrophy of mouse models were confirmed by HE staining (Fig. 2A). In order to investigate the CYP1B1 mRNA level, total RNA was isolated from the heart tissues and detected using RT-PCR. As presented in Fig. 2B, the CYP1B1 mRNA levels were significantly increased in the CKD and IS groups compared with the control $(\mathrm{P}<0.05)$. The heart tissues from these groups were then assessed via western blot analysis and the results revealed that the CYP1B1 protein levels were significantly increased in the CKD and IS groups when compared with those in the normal control group $(\mathrm{P}<0.05$; Fig. 2C). Similarly, the mRNA levels 


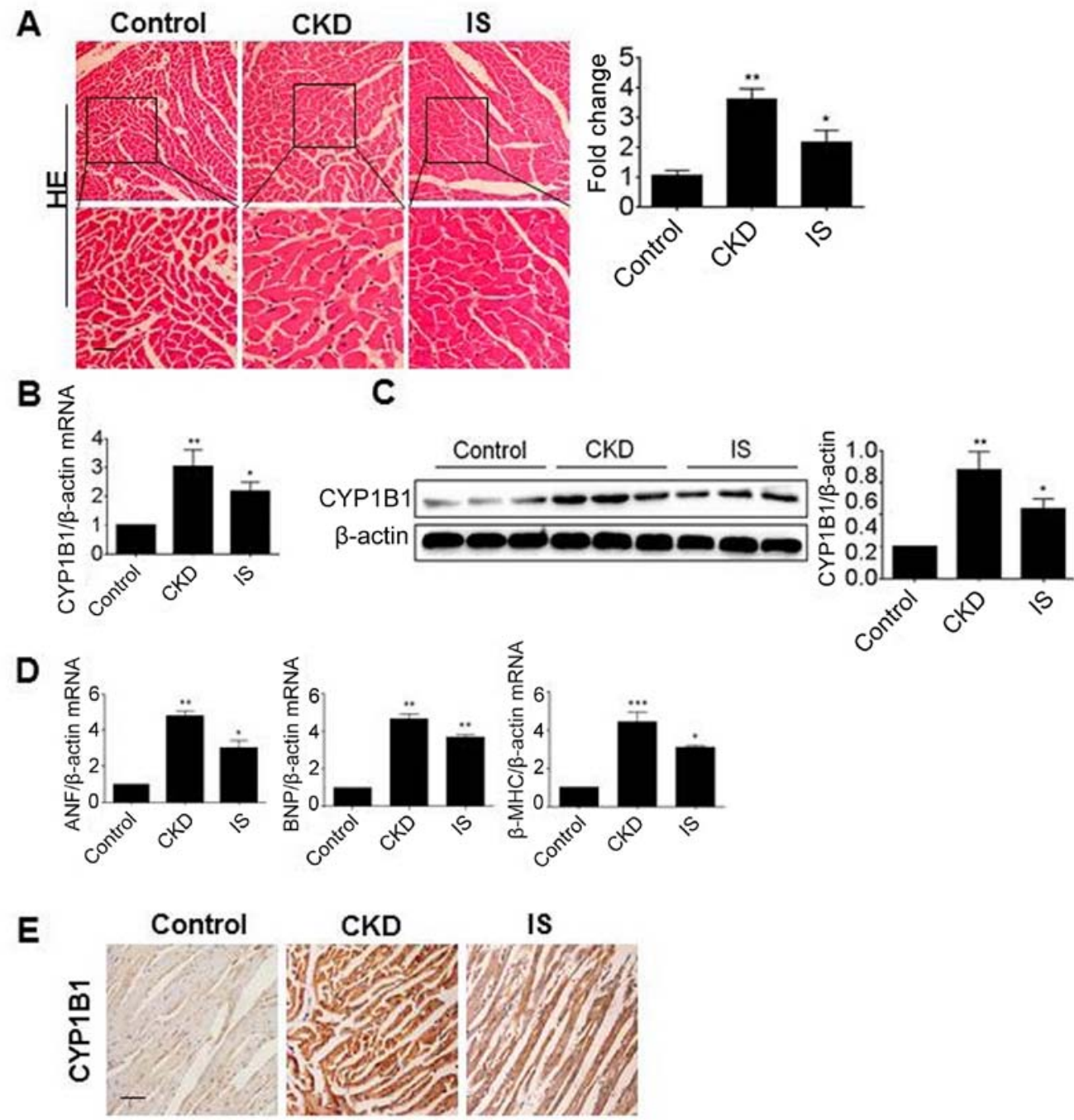

Figure 2. Gene expression of CYP1B1 in CKD or IS-treated mice. (A) Heart tissues from control, CKD and IS-treated mouse were stained using HE. Scale bar, $200 \mu \mathrm{m}$. RNA and protein samples were obtained from the heart tissues of control, CKD and IS-treated mice, and CYP1B1 expression was detected using (B) RT-PCR and (C) western blot analysis. (D) RNA samples were detected using RT-PCR for ANF, BNP and $\beta$-MHC. (E) Paraffin sections from the heart tissues were detected using immunohistochemistry with antibodies against CYP1B1. ${ }^{*} \mathrm{P}<0.05,{ }^{* * *} \mathrm{P}<0.01$ and ${ }^{* * * *} \mathrm{P}<0.001$ vs. the control. Scale bar, $100 \mu \mathrm{m}$. CKD, chronic kidney disease; IS, indoxyl sulfate; CYP1B1, cytochrome P450 family 1 subfamily B member 1; HE, hematoxylin and eosin; RT-PCR, reverse transcription-polymerase chain reaction; ANF, atrial natriuretic factor; BNP, brain natriuretic peptide; $\beta$-MHC, $\beta$-myosin heavy chain.

of ANF, BNF and $\beta$-MHC were also significantly increased in these two groups, compared with that in controls $(\mathrm{P}<0.05$; Fig. 2D). To further confirm the gene expression of CYP1B1 in vivo, sections from the heart tissues were detected using immunochemistry. As presented in Fig. 2E, CYP1B1 was substantially increased in the CKD and IS groups compared with the control, which was consistent with the results of the western blot analysis. These data clearly demonstrated that the expression of CYP1B1 was induced by IS in vivo.

Nuclear translocation of AhR induced by IS. The present study then investigated whether the induction of CYP1B1 by IS is dependent on AhR. Thus, the effect of IS on the protein expression of AhR in $\mathrm{H} 9 \mathrm{c} 2$ cells was examined. However, the total protein of AhR was not significantly altered by IS treatment, even at the maximal dose of IS (Fig. 3A). Similarly, the total protein and mRNA levels of AhR remained unchanged when the cells were treated with CKD serum (Fig. S2). The protein samples were further assessed to isolate the nuclear and cytosol proportions. Notably, the cytosol AhR level was significantly decreased compared with the control $(\mathrm{P}<0.05)$ while the nuclear AhR level was significantly increased compared with the control $(\mathrm{P}<0.05)$, indicating that nuclear translocation of AhR occurs in a dose-dependent manner (Fig. 3B and C). In order to further confirm this result, the cellular distribution of AhR was detected using immunofluorescence. As presented in Fig. 3D, AhR was detected as smeared in the cytosol in control cells. However, following the treatment of IS, AhR was visible as dotted foci in the nucleus of the $\mathrm{H} 9 \mathrm{c} 2$ cells, which indicated the marked nuclear translocation of AhR induced by IS.

ChIP analysis of the binding of AhR in the promoter region of CYP1B1. AhR is able to bind with the ARNT to form a heterodimeric transcription factor, which is responsible for the induction of a number of different targets (15). It was further investigated whether AhR may directly bind to the promoter region of CYP1B1. Therefore, ChIP-PCR was performed in 
A
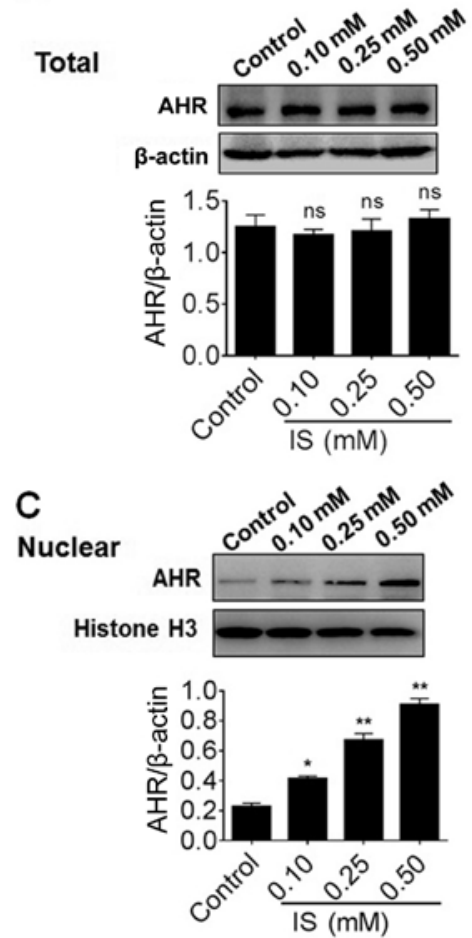

B

Cytosol
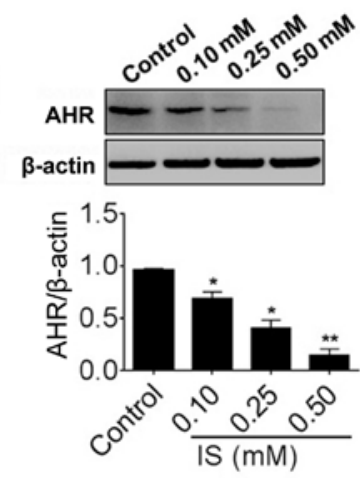

D

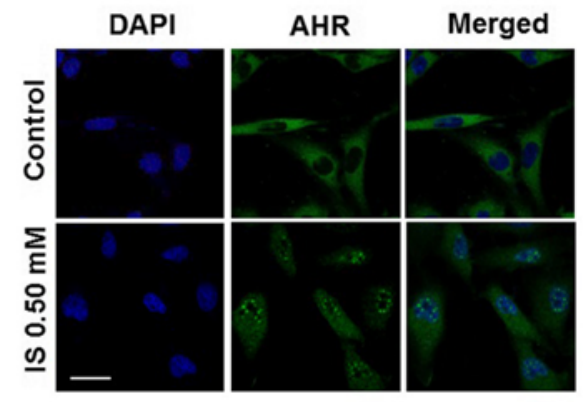

Figure 3. Nuclear translocation of AhR induced by IS. Once H9c2 cells were treated with increasing concentrations of IS, (A) total and fractional protein samples for (B) the cytosol and (C) the nucleus were isolated and detected via western blot analysis for AhR expression. (D) H9c2 cells on slides were treated with IS $(0.5 \mathrm{mM})$ and cellular distribution of AhR was analyzed by immunofluorescence. ${ }^{*} \mathrm{P}<0.01$ and ${ }^{* * * *} \mathrm{P}<0.001 \mathrm{vs}$. the control. Scale bar, $50 \mu \mathrm{m}$. AhR, aryl hydrocarbon receptor; IS, indoxyl sulfate; ns, not significant.

order to analyze the location of $\mathrm{AhR}$ in the promoter region (P1) and the intron 2 (I2) of CYP1B1 (Fig. 4A). Following IS treatment, $\mathrm{H} 9 \mathrm{c} 2$ cells were immunoprecipitated with antibodies against AhR, IgG (negative control) and histone H3 (positive control). The immunoprecipitated DNA was detected via PCR and positive bands of primer pair P1 were detected in the immunoprecipitated samples of AhR and histone $\mathrm{H} 3$, but not in IgG (Fig. 4B, lower panel). Of note, the band of primer pair I2 was only visible in immunoprecipitated samples of histone $\mathrm{H} 3$, indicating the specific binding of $\mathrm{AhR}$ in the promoter region (Fig. 4B, upper panel). RT-qPCR was further applied to detect the enrichment of AhR. As presented in Fig. 4C and D, significantly increased amounts of AhR-binding DNA were detected in IS-treated cells compared with the negative control $(\mathrm{P}<0.001)$. Overall, the data in the present study clearly demonstrated that AhR was able to bind with the promoter region of CYP1B1 and this binding was enhanced by IS treatment.

Effect of AhR knockdown on induction of CYPIBI by IS. To further prove that AhR is crucial for the induction of CYP1B1 by IS, siRNAs of AhR were used to treat $\mathrm{H} 9 \mathrm{c} 2$ cells. Compared with NC-siRNA, si-AhR-2 had the greatest significant efficiency when inhibiting the expression of $A h R$ and was used in the subsequent experiments $(\mathrm{P}<0.001$; Fig. 5A). H9c2 cells were pre-treated with si-AhR or its control prior to IS treatment, and the gene expression of CYP1B1 was detected. It was revealed that the pretreatment of si-AhR significantly reversed the induction of CYP1B1 protein and mRNA induced by IS $(\mathrm{P}<0.01$; Fig. $5 \mathrm{~B}$ and $\mathrm{C})$. Accordingly, the transcription of cardiac hypertrophy markers including ANF, BNF and
$\beta$-MHC was also reversed by si-AhR ( $\mathrm{P}<0.05$; Fig. 5D). Thus, AhR knockdown attenuated the induction of CYP1B1 by IS, and prevented cardiac hypertrophy.

Effect of CYPIB1 knockdown on cardiac hypertrophy induced by $I S$. In order to elucidate the association between CYP1B1 expression and cardiac hypertrophy, siRNAs of CYP1B1 were synthesized and used to knockdown the expression of CYP1B1 in $\mathrm{H} 9 \mathrm{c} 2$ cells. It was revealed that si-CYP1B1-2 was the optimum siRNA for inhibiting the expression of CYP1B1, and was therefore used in subsequent experiments (Fig. 6A). Furthermore, the pretreatment of si-CYP1B1 significantly reversed the induction of CYP1B1 protein induced by IS $(\mathrm{P}<0.01$; Fig. $6 \mathrm{~B})$. In order to gain an improved understanding of this association, $\mathrm{H} 9 \mathrm{c} 2$ cells were pretreated with si-CYP1B1 prior to IS treatment, and the gene expression of ANF, BNF and $\beta$-MHC was detected via RT-PCR. As presented in Fig. 6C, the induction of all these cardiac hypertrophy markers was significantly reversed by pretreatment with si-CYP1B1 (P<0.01; Fig. 6C). In addition, the cell size was determined by immunofluorescence staining using $\alpha$-actinin antibodies. The results revealed that the cell size induced by IS treatment was significantly inhibited by si-CYP1B1 ( $\mathrm{P}<0.01$; Fig. 6D). This suggested that CYP1B1 knockdown inhibited cardiac hypertrophy.

Effect of CYP1B1 inhibition in vivo. Finally, in order to investigate the function of CYP1B1 inhibition in vivo, a specific inhibitor of CYP1B1 was combined with IS for use in the mouse model. Previous studies $(21,27)$ have reported TMS as a selective inhibitor of CYP1B1, and the dosage in vivo was 
A

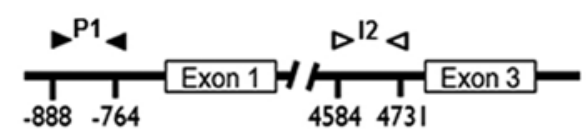

C

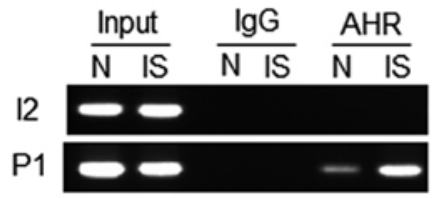

B
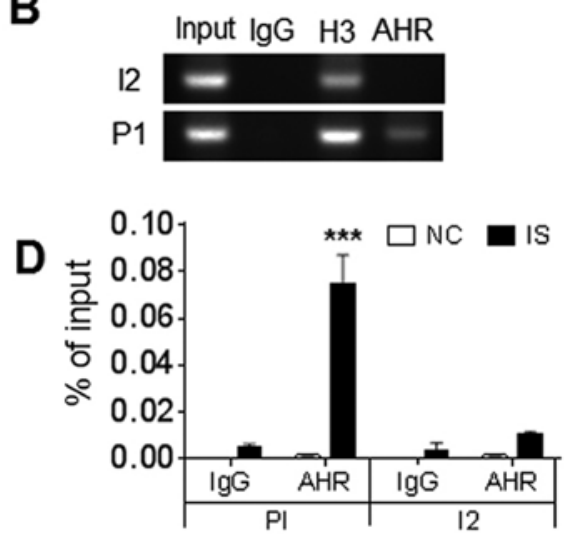

Figure 4. ChIP analysis of the binding of AhR in the promoter region of CYP1B1. (A) Diagram of the CYP1B1 promoter and the intron region. Black and white arrows indicate the locations of the ChIP-PCR primers. The transcriptional start site in the promoter region was considered to be +1 . (B) IS-treated H9c2 cells and controls were harvested for ChIP analysis with antibodies against AhR, histone H3 (positive control) or normal rabbit IgG (negative control). The immunoprecipitated DNA and input DNA were detected by routine PCR. The immunoprecipitated DNA and input DNA were detected by (C) semi-quantitative PCR or reverse transcription-PCR. (D) Data were displayed as the percentage of input DNA. ${ }^{* * *} \mathrm{P}<0.001$ vs. the negative control. N, control; ChIP, chromatin immunoprecipitation; AhR, aryl hydrocarbon receptor; CYP1B1, cytochrome P450 family 1 subfamily B member 1; PCR, polymerase chain reaction; IgG, immunoglobulin G; IS, indoxyl sulfate; P1, promoter region; I2, intron 2.

A

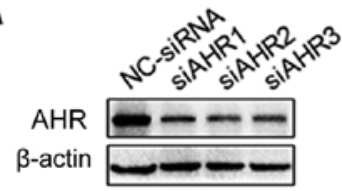

C

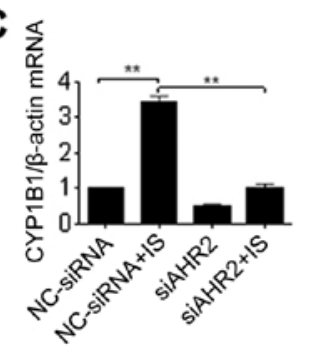

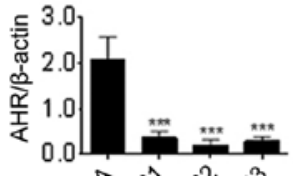

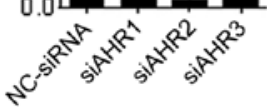

D

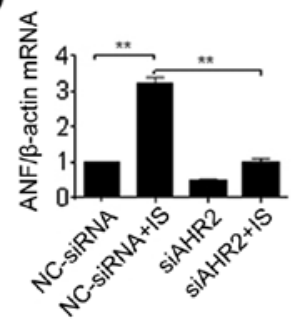

B
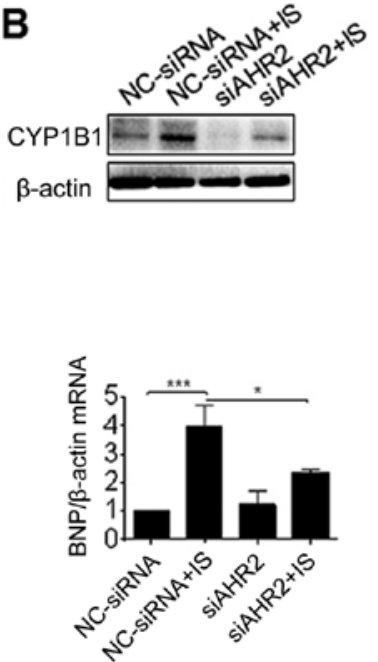
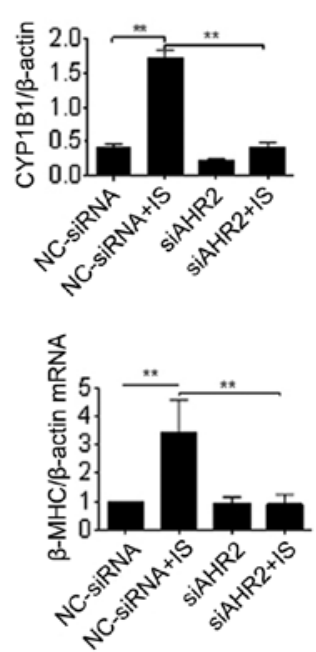

Figure 5. Effect of AhR knockdown on the induction of CYP1B1 by IS. (A) H9c2 cells were transfected with siRNA against AhR (siAHR1-3) or control (NC-siRNA) for 2 days, and protein samples were prepared for western blot analysis. H9c2 cells were pretreated with siRNA and further incubated with IS media for 3 days, then total proteins and RNA were isolated for (B) western blot analysis and (C) RT-PCR analysis of AhR expression. (D) RNA samples were detected using RT-PCR analysis of ANF, BNP and $\beta$-MHC expression. ${ }^{*} \mathrm{P}<0.05,{ }^{* *} \mathrm{P}<0.01$ and ${ }^{* * *} \mathrm{P}<0.001$ with comparisons shown by lines. AhR, aryl hydrocarbon receptor; CYP1B1, cytochrome P450 family 1 subfamily B member 1; IS, indoxyl sulfate; siRNA, small interfering RNA; NC, negative control; RT-PCR, reverse transcription-polymerase chain reaction; ANF, atrial natriuretic factor; BNP, brain natriuretic peptide; $\beta$-MHC, $\beta$-myosin heavy chain.

selected according to these studies. Following 2 months of treatment, the thickness of the ventricular wall and the relative heart weight in the IS group were significantly increased, compared with that in the controls $(\mathrm{P}<0.01)$. However, these parameters were significantly ameliorated by TMS treatment $(\mathrm{P}<0.05$; Fig. $7 \mathrm{~A}$ and $\mathrm{B})$. Furthermore, the results of the HE staining revealed that the decreased length of the left ventricular midchamber and the increased cell size induced by IS were also substantially ameliorated by TMS treatment (Fig. 7C). In addition, the increased mRNA levels of cardiac hypertrophy markers induced by IS were significantly reversed by TMS treatment $(\mathrm{P}<0.001$; Fig. 7D). These results clearly indicate that the inhibition of CYP1B1 ameliorated cardiac hypertrophy induced by IS.

\section{Discussion}

CYP1B1 is a member of the CYP1 subfamily, and also the most abundantly expressed CYP gene in human hearts (28). It has been reported that CYP1B1 contributes to the development of hypertension and renal dysfunction in male mice (29). Furthermore, mutations in this gene have been associated with primary congenital glaucoma (30). As a monooxygenase, it catalyzes a number of reactions involved in drug metabolism and the synthesis of cholesterol, steroids and other lipids (31). This enzyme has been reported to metabolize procarcinogens, including polycyclic aromatic hydrocarbons and 17 $\beta$-estradiol (21). The functions of CYP1B1 have been extensively studied in cancer, due to its bioactivity 

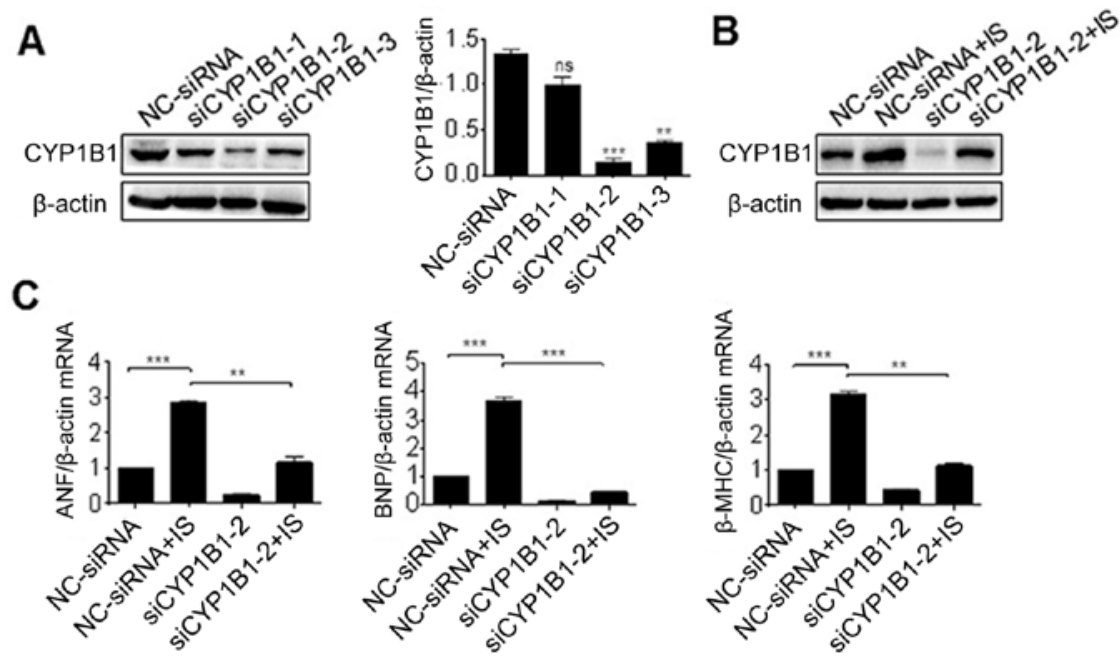

D
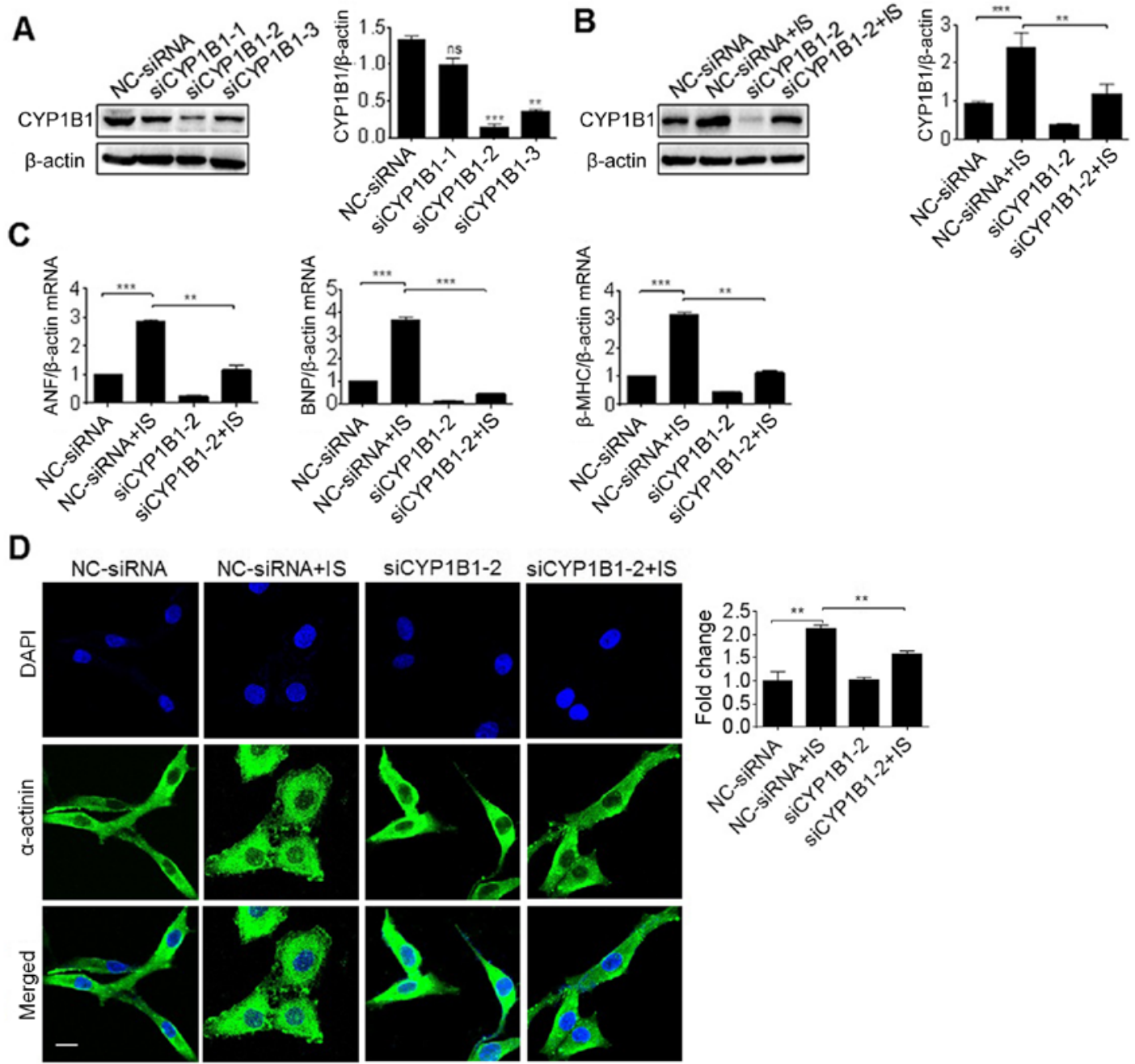

Figure 6. Effect of CYP1B1 knockdown on cardiac hypertrophy induced by IS. (A) H9c2 cells were transfected with siRNA against CYP1B1 (siCYP1B1-1 3) or control (NC-siRNA) for 2 days, and protein samples were then prepared for the western blot analysis. H9c2 cells were pretreated with siRNA and further incubated with IS media for 3 days, then total proteins and RNA were subjected to (B) the western blot analysis and (C) reverse transcription-polymerase chain reaction analysis of ANF, BNP and $\beta$-MHC expression. (D) Similar treated H9c2 cells on slides were detected by immunofluorescence with antibodies against of $\alpha$-actinin. ${ }^{* *} \mathrm{P}<0.01$ and ${ }^{* * *} \mathrm{P}<0.001$ with comparisons shown by lines. Scale bar, $50 \mu \mathrm{m}$. ns, not significant; CYP1B1, cytochrome P450 family 1 subfamily B member 1; IS, indoxyl sulfate; siRNA, small interfering RNA; NC, negative control; ANF, atrial natriuretic factor; BNP, brain natriuretic peptide; $\beta$-MHC, $\beta$-myosin heavy chain.

and overexpression in a variety of different types of human tumor (32). Furthermore, the association between CYP1B1 polymorphisms and cancer has been extensively studied. For example, an association between the CYP1B1-rs1056836 genetic polymorphism and clinical features of esophageal squamous cell carcinoma was identified in an Iranian Mashhad cohort study (33). In addition, a single nucleotide polymorphism in CYP1B1 resulted in differential prostate cancer risk and telomere length (34). As it metabolizes AA to mid-chain HETEs with vascular deleterious effects, studies have also demonstrated that there is an association between CYP1B1 and cardiac diseases. Previous studies have demonstrated that CYP1B1 was significantly induced in the left ventricular tissue of spontaneously hypertensive rats and in drug-induced hypertrophied hearts (35-37). In the present study, it was revealed that CYP1B1 expression may be efficiently induced by IS and CKD serum via the AhR pathway. In addition, it was demonstrated that CYP1B1 knockdown or inhibition with TMS may reverse cardiac hypertrophy induced by IS in in vitro and in vivo studies. These results further confirmed the association between CYP1B1 and cardiac diseases.

Lower estimated glomerular filtration rate (eGFR) has been accepted as an independent risk factor for CVD (38). It is well known that various metabolites, or so-called uremic toxins, are detained in the body as the GFR declines. A number of these have been confirmed as having cardiovascular toxicity, including IS. As a typical protein-bound uremic toxin, IS is a tryptophan-derived uremic toxin $(8,39,40)$. Tryptophan, an essential amino acid in the diet, may be metabolized by tryptophanase to indole in the gut where IS is absorbed, and further converted into IS in the liver (41). A gradual rise in serum IS was observed in CKD development from the earliest stages of the disease, and higher serum IS levels predicted higher overall and cardiovascular mortality risk, which was independent of age, sex, diabetes mellitus, phosphate, albumin and hemoglobin levels, vascular stiffness and aortic calcification (42). In the present study, the concentration of serum IS from patients with $\mathrm{CDK}$ varied from $125.8-356.1 \mu \mathrm{M}$ (data 
A

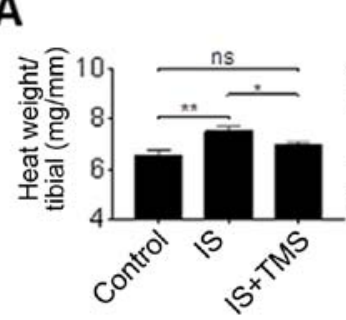

B

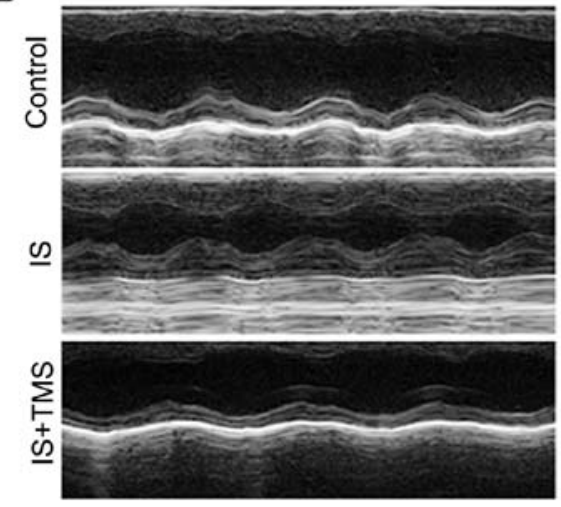

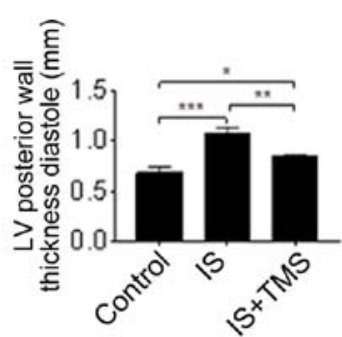

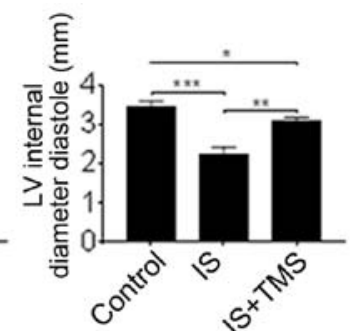

C

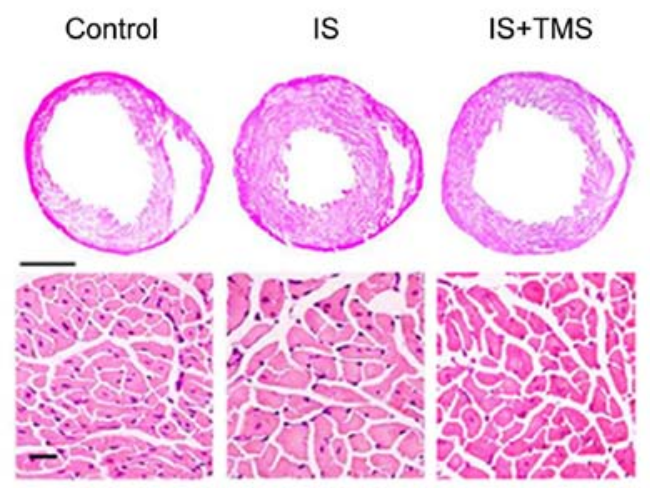

D

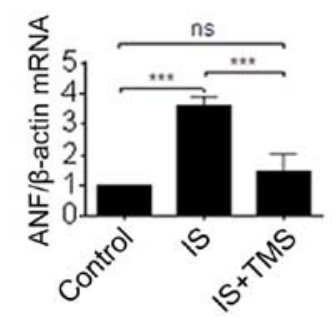

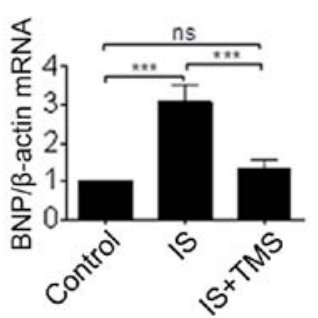

Figure 7. Effect of CYP1B1 inhibitor on cardiac hypertrophy in vivo. (A) Mice were treated with IS or/and CYP1B1 inhibitor (TMS) for 8 weeks and (B) the LV hypertrophy was determined by echocardiography. (C) Gross pathology of the midchamber sections of the heart was stained using hematoxylin and eosin. Scale bar, $200 \mathrm{~mm}$ in the upper panel and $50 \mu \mathrm{m}$ in the lower panel. (D) Gene expression of the cardiac hypertrophy markers in mouse heart tissues were detected using a reverse transcription-polymerase chain reaction. ${ }^{*} \mathrm{P}<0.05,{ }^{* *} \mathrm{P}<0.01$ and ${ }^{* * *} \mathrm{P}<0.001$ with comparisons shown by lines. ns, not significant; CYP1B1, cytochrome P450 family 1 subfamily B member 1; IS, indoxyl sulfate; ANF, atrial natriuretic factor; BNP, brain natriuretic peptide; $\beta$-MHC, $\beta$-myosin heavy chain; LV, left ventricular; TMS, 2,4,3',5'-tetramethoxystilbene.

not shown), which was markedly higher compared with the normal value. Previous studies indicated that the serum levels of IS were independently associated with LVH, and IS-induced cardiomyocyte hypertrophy was identified in vitro and was further confirmed by the intraperitoneal injection of IS in mice (9), which is consistent with other research results $(43,44)$. Furthermore, IS was demonstrated to induce increased ROS production, which inhibited the p38, extracellular signal-regulated kinase 1/2 and AMPK/UCP2 signaling pathway and then promote LVH development (10). But the signaling pathways associated with IS exposure have not yet been fully understood.

Previous studies have demonstrated that IS is a human AhR ligand and a potent activator of its transcriptional activity, and that there is an association between the deleterious effects of IS and AhR activation (45-47). Expression of AhR is relatively high in the lungs, placenta, spleen, pancreas and liver, and relatively low in the heart, brain and skeletal muscles in adults (48). Despite the low expression level of AhR in the heart, AhR does have noticeable effects on the physiological functioning of the heart. It exists as an AhR molecular chaperone complex comprising an AhR, two heat shock protein 90 and $\mathrm{X}$-associated protein 2 and 23 in the cytosol $(49,50)$. Following binding with ligands, AhR translocates from the cytosol to the nucleus where it disassociates from the complex. In the present study, the nuclear translocation of AhR induced by IS was demonstrated via western blot analysis and an immunofluorescence assay (Fig. 3), which was consistent with previous studies. Subsequently, the ligand-AhR complex combines with ARNT and binds to DRE or XRE, promoting the transcription of a large number of target genes activating and triggering a number of biological or toxicological effects. In fact, other uremic toxins, including indole-3-acetic acid (IAA) and p-cresyl sulfate, are also thought to be potent activators of AhR transcriptional activity under uremic conditions (51). Likewise, IAA was reported to induce endothelial inflammation and oxidative stress, and activate the inflammatory $\mathrm{AhR} / \mathrm{p} 38$ mitogen-activated protein kinase/nuclear factor- $\kappa \mathrm{B}$ pathway (52). In using the ChIP analysis in the present study, it was revealed that AhR may bind with the promoter region of CYP1B1, but not with the intron (Fig. 4). This suggested that AhR activation may occur in patients with CKD. 
In addition to the classical signaling pathway, AhR may also interact with other pathways by competing for transcriptional co-activators or co-repressors. The present study focused on the AhR-CYP1B1 pathway. Other non-classical AhR signaling pathways may also be associated with cardiac hypertrophy induced by IS. Notably, the function of AhR in cardiac hypertrophy is controversial, as marked cardiac hypertrophy was observed in AhR-deficient mice and the underlying molecular mechanism may be associated with an elevated level of vascular endothelial growth factor in AhR-deficient mice $(53,54)$. These studies suggest that the effects of AhR on the cardiovascular system are greater than expected. One explanation may be that the AhR deficiency model is not suitable for analyzing its pathophysiological function, as AhR is vital for the development of the heart (55). Although there are contradictions among currently available studies, the functions of AhR signaling in cardiac hypertrophy are important.

A previous study has indicated that CYP1B1 polymorphisms are closely associated with cardiac disease; the association between two common CYP1B1 polymorphisms, CYP1B1*3 and CYP1B1*4, and the risk of CVD was reported in a large population of 50,000 individuals (56). However, to the best of our knowledge, there are currently no reports regarding the effects of these polymorphisms on AA metabolism. One of the reasons that the induction of CYP1B1 results in cardiac hypertrophy is that it may give rise to a higher level of deleterious metabolites. Previous studies have demonstrated that CYP1B1 is able to metabolize AA to mid-chain HETEs, of which the vascular deleterious effects have been extensively investigated $(17,57,58)$. For example, the increased levels of mid-chain HETE metabolism were associated with increased CYP1B1 expression in a rat model of pressure overload cardiac hypertrophy (59). Although the present study did not assess HETE metabolism, it is rational to speculate that these deleterious metabolisms are involved in cardiac hypertrophy induced by IS, which will be investigated in future studies. Another reason may be that CYP1B1 may generate a higher level of superoxide radicals. It has previously been reported that CYP1B1 served an important function in the activation of NADPH oxidase, which was thought to generate ROS. This was evident by the result that CYP1B1 siRNA inhibited AA-induced increases in NADPH oxidase activity (60). A previous study also demonstrated that IS may induce ROS production. Thus it is believable that CYP1B1 contributes to the generation of ROS.

One limitation of present study is that cardiac hypertrophy was not measured in these patients. The main purpose of the present study was to assess the biological effects of CKD serum on cell culture, including cell proliferation, apoptosis and its associated gene expression. However, CKD is recognized as a strong and independent risk factor for developing CVD, which has been confirmed in numerous studies $(3,5,61)$. Therefore, the present study did not measure cardiac hypertrophy.

In summary, the present study revealed that the expression of the CYP1B1 gene was induced by CKD serum and IS, which was associated with the AhR pathway. CYP1B1 was involved in cardiac hypertrophy under uremic conditions, which may be a potential therapy target for cardiovascular disease among patients with CKD. Thus, the present study provided evidence to support another molecular mechanism underlying cardiac hypertrophy induced by the uremic toxin.

\section{Acknowledgements}

Not applicable.

\section{Funding}

The present study was supported by the National Key R\&D Program of China (grant nos. 2018YFC1312700 and 2017YFA0106600), the Natural Science Foundation of China (grant nos. 81873605, 81800468, 81700379, 81400747 and 81800616), the Personal Training Program for Clinical Medicine Research of Army Medical University (grant no. 2018XLC1007) and the Frontier specific projects of Xinqiao Hospital (grant no. 2018YQYLY004).

\section{Availability of data and materials}

All data generated or analyzed during the present study are available from the corresponding author upon reasonable request.

\section{Authors' contributions}

LN, JZ and BZ designed the study. YZ, SW, YH, KY and YL performed the experiments. XB, CL and JX analyzed and interpreted the data. JZ made substantial contributions to the design and supervision of the present study. LN wrote the manuscript. All authors reviewed the results and approved the final version of the manuscript.

\section{Ethics approval and consent to participate}

The present study was approved by the Ethics Committee of Xinqiao Hospital, Army Medical University, and written informed consent was obtained from the patients. The animal protocol was approved by the Animal Care and Use Committee of Army Medical University.

\section{Patient consent for publication}

Written informed consent for publication was obtained from enrolled patients.

\section{Competing interests}

The authors declare that they have no competing interests.

\section{References}

1. Chen SC, Huang JC, Su HM, Chiu YW, Chang JM, Hwang SJ and Chen HC: Prognostic cardiovascular markers in chronic kidney disease. Kidney Blood Press Res 43: 1388-1407, 2018.

2. Cunningham MW Jr and LaMarca B: Risk of cardiovascular disease, end-stage renal disease, and stroke in postpartum women and their fetuses after a hypertensive pregnancy. Am J Physiol Regul Integr Comp Physiol 315: R521-R528, 2018.

3. Shah SR and Winchester DE: The impact of chronic kidney disease on medication choice and pharmacologic management in patients with heart failure. Expert Rev Clin Pharmacol 11: 571-579, 2018.

4. Siedlecki AM, Jin X and Muslin AJ: Uremic cardiac hypertrophy is reversed by rapamycin but not by lowering of blood pressure. Kidney Int 75: 800-808, 2009.

5. Sethna CB, Merchant K and Reyes A: Cardiovascular disease risk in children with kidney disease. Semin Nephrol 38: 298-313, 2018. 
6. Kim H, Yoo TH, Choi KH, Oh KH, Lee J, Kim SW, Kim TH, Sung S, Han SH; KNOW-CKD Group: Baseline cardiovascular characteristics of adult patients with chronic kidney disease from the korean cohort study for outcomes in patients with chronic kidney disease (KNOW-CKD). J Korean Med Sci 32: 231-239, 2017.

7. Lash JP, Go AS, Appel LJ, He J, Ojo A, Rahman M, Townsend RR, Xie D, Cifelli D, Cohan J, et al: Chronic Renal Insufficiency Cohort (CRIC) Study: Baseline characteristics and associations with kidney function. Clin J Am Soc Nephrol 4: 1302-1311, 2009

8. Gao H and Liu S: Role of uremic toxin indoxyl sulfate in the progression of cardiovascular disease. Life Sci 185: 23-29, 2017.

9. Yang K, Wang C, Nie L, Zhao X, Gu J, Guan X, Wang S, $\mathrm{Xiao} \mathrm{T}, \mathrm{Xu} \mathrm{X}, \mathrm{He} \mathrm{T}$, et al: Klotho protects against indoxyl sulphate-induced myocardial hypertrophy. J Am Soc Nephrol 26 2434-2446, 2015.

10. Yang K, Xu X, Nie L, Xiao T, Guan X, He T, Yu Y, Liu L, Huang $\mathrm{Y}$, Zhang $\mathrm{J}$ and Zhao J: Indoxyl sulfate induces oxidative stress and hypertrophy in cardiomyocytes by inhibiting the AMPK/UCP2 signaling pathway. Toxicol Lett 234: 110-119, 2015.

11. Six I, Gross P, Rémond MC, Chillon JM, Poirot S, Drueke TB and Massy ZA: Deleterious vascular effects of indoxyl sulfate and reversal by oral adsorbent AST-120. Atherosclerosis 243: 248-256, 2015

12. Yoshifuji A, Wakino S, Irie J, Matsui A, Hasegawa K, Tokuyama H, Hayashi K and Itoh H: Oral adsorbent AST-120 ameliorates gut environment and protects against the progression of renal impairment in CKD rats. Clin Exp Nephrol 22: 1069-1078, 2018.

13. Kamiński T, Michałowska M and Pawlak D: Aryl hydrocarbon receptor (AhR) and its endogenous agonist-indoxyl sulfate in chronic kidney disease. Postepy Hig Med Dosw (Online) 71: 624-632, 2017.

14. Wheeler MA, Rothhammer V and Quintana FJ: Control of immune-mediated pathology via the aryl hydrocarbon receptor. J Biol Chem 292: 12383-12389, 2017.

15. Al-Dhfyan A, Alhoshani A and Korashy HM: Aryl hydrocarbon receptor/cytochrome P450 1A1 pathway mediates breast cancer stem cells expansion through PTEN inhibition and $\beta$-Catenin and Akt activation. Mol Cancer 16: 14, 2017.

16. Korashy HM and El-Kadi AO: The role of aryl hydrocarbon receptor in the pathogenesis of cardiovascular diseases. Drug Metab Rev 38: 411-450, 2006.

17. El-Sherbeni AA and El-Kadi AO: Repurposing resveratrol and Fluconazole to modulate human cytochrome P450-mediated arachidonic acid metabolism. Mol Pharm 13: 1278-1288, 2016.

18. Yaghini FA, Song CY, Lavrentyev EN, Ghafoor HU, Fang XR Estes AM, Campbell WB and Malik KU: Angiotensin II-induced vascular smooth muscle cell migration and growth are mediated by cytochrome P450 1B1-dependent superoxide generation. Hypertension 55: 1461-1467, 2010.

19. Althurwi HN, Tse MM, Abdelhamid G, Zordoky BN Hammock BD and El-Kadi AO: Soluble epoxide hydrolase inhibitor, TUPS, protects against isoprenaline-induced cardiac hypertrophy. Br J Pharmacol 168: 1794-1807, 2013.

20. Elkhatali S, Maayah Z, El-Sherbeni AA, Elshenawy $\mathrm{OH}$, Abdelhamid G, Shoieb SM and El-Kadi AOS: Inhibition of Mid-chain HETEs protects against angiotensin II-induced cardiac hypertrophy. J Cardiovasc Pharmacol 70: 16-24, 2017.

21. Maayah ZH, Althurwi HN, El-Sherbeni AA, Abdelhamid G Siraki AG and El-Kadi AO: The role of cytochrome P450 1B1 and its associated mid-chain hydroxyeicosatetraenoic acid metabolites in the development of cardiac hypertrophy induced by isoproterenol. Mol Cell Biochem 429: 151-165, 2017.

22. Gondouin B, Cerini C, Dou L, Sallée M, Duval-Sabatier A, Pletinck A, Calaf R, Lacroix R, Jourde-Chiche N, Poitevin S, et al: Indolic uremic solutes increase tissue factor production in endothelial cells by the aryl hydrocarbon receptor pathway. Kidney Int 84: 733-744, 2013.

23. Livak KJ and Schmittgen TD: Analysis of relative gene expression data using real-time quantitative PCR and the 2(-Delta Delta C(T)) method. Methods 25: 402-408, 2001

24. Pang X, He G, Luo C, Wang Y and Zhang B: Knockdown of Rad9A enhanced DNA damage induced by trichostatin A in esophageal cancer cells. Tumour Biol 37: 963-970, 2016.

25. Deltombe O, Van Biesen W, Glorieux G, Massy Z, Dhondt A and Eloot $\mathrm{S}$ : Exploring protein binding of uremic toxins in patients with different stages of chronic kidney disease and during hemodialysis. Toxins (Basel) 7: 3933-3946, 2015.
26. Adesso S, Popolo A, Bianco G, Sorrentino R, Pinto A, Autore G and Marzocco S: The uremic toxin indoxyl sulphate enhances macrophage response to LPS. PLoS One 8: e76778, 2013.

27. Jennings BL, Montanez DE, May ME Jr, Estes AM, Fang XR, Yaghini FA, Kanu A and Malik KU: Cytochrome P450 1B1 contributes to increased blood pressure and cardiovascular and renal dysfunction in spontaneously hypertensive rats. Cardiovasc Drugs Ther 28: 145-161, 2014.

28. Jennings BL, George LW, Pingili AK, Khan NS, Estes AM, Fang XR, Gonzalez FJ and Malik KU: Estrogen metabolism by cytochrome P450 1B1 modulates the hypertensive effect of angiotensin II in female mice. Hypertension 64: 134-140, 2014.

29. Pingili AK, Thirunavukkarasu S, Kara M, Brand DD, Katsurada A, Majid DS, Navar LG, Gonzalez FJ and Malik KU: $6 \beta$-hydroxytestosterone, a cytochrome P450 1B1-testosteronemetabolite, mediates angiotensin II-induced renal dysfunction in male mice. Hypertension 67: 916-926, 2016.

30. Jennings BL, Anderson LJ, Estes AM, Fang XR, Song CY, Campbell WB and Malik KU: Involvement of cytochrome P-450 $1 \mathrm{~B} 1$ in renal dysfunction, injury, and inflammation associated with angiotensin II-induced hypertension in rats. Am J Physiol Renal Physiol 302: F408-F420, 2012.

31. Li F, Zhu W and Gonzalez FJ: Potential role of CYP1B1 in the development and treatment of metabolic diseases. Pharmacol Ther 178: 18-30, 2017.

32. D'Uva G, Baci D, Albini A and Noonan DM: Cancer chemoprevention revisited: Cytochrome $\mathrm{P} 450$ family $1 \mathrm{~B} 1$ as a target in the tumor and the microenvironment. Cancer Treat Rev 63: $1-18,2018$.

33. Moghadam AR, Mehramiz M, Entezari M, Aboutalebi H, Kohansal F, Dadjoo P, Fiuji H, Nasiri M, Aledavood SA, Anvari K, et al: A genetic polymorphism in the CYP1B1 gene in patients with squamous cell carcinoma of the esophagus: An Iranian Mashhad cohort study recruited over 10 years. Pharmacogenomics 19: 539-546, 2018

34. Gu CY, Li GX, Zhu Y, Xu H, Zhu Y, Qin XJ, Bo D and Ye DW: A single nucleotide polymorphism in CYP1B1 leads to differential prostate cancer risk and telomere length. J Cancer 9: 269-274, 2018

35. Tse MM, Aboutabl ME, Althurwi HN, Elshenawy OH, Abdelhamid G and El-Kadi AO: Cytochrome P450 epoxygenase metabolite, 14,15-EET, protects against soproterenol-induced cellular hypertrophy in $\mathrm{H} 9 \mathrm{c} 2$ rat cell line. Vasc Pharmacol 58: 363-373, 2013

36. Thum T and Borlak J: Testosterone, cytochrome P450, and cardiac hypertrophy. FASEB J 16: 1537-1549, 2002.

37. Maayah ZH and El-Kadi AO: The role of mid-chain hydroxyeicosatetraenoic acids in the pathogenesis of hypertension and cardiac hypertrophy. Arch Toxicol 90: 119-136, 2016.

38. Evans M, Grams ME, Sang Y, Astor BC, Blankestijn PJ, Brunskill NJ, Collins JF, Kalra PA, Kovesdy CP, Levin A, et al: Risk Factors for Prognosis in Patients With Severely Decreased GFR. Kidney Int Rep 3: 625-637, 2018.

39. Savira F, Magaye R, Hua Y, Liew D, Kaye D, Marwick T and Wang BH: Molecular mechanisms of protein-bound uremic toxin-mediated cardiac, renal and vascular effects: Underpinning intracellular targets for cardiorenal syndrome therapy. Toxicol Lett 308: 34-49, 2019

40. Guo J, Lu L, Hua Y, Huang K, Wang I, Huang L, Fu Q, Chen A, Chan P, Fan H, et al: Vasculopathy in the setting of cardiorenal syndrome: Roles of protein-bound uremic toxins. Am J Physiol Heart Circ Physiol 313: H1-H13, 2017.

41. Niwa T: Uremic toxicity of indoxyl sulfate. Nagoya J Med Sci 72: $1-11,2010$.

42. Barreto FC, Barreto DV, Liabeuf S, Meert N, Glorieux G, Temmar M, Choukroun G, Vanholder R and Massy ZA: European Uremic Toxin Work Group (EUTox): Serum indoxyl sulfate is associated with vascular disease and mortality in chronic kidney disease patients. Clin J Am Soc Nephrol 4: 1551-1558, 2009.

43. Lekawanvijit S, Adrahtas A, Kelly DJ, Kompa AR, Wang BH and Krum H: Does indoxyl sulfate, a uraemic toxin, have direct effects on cardiac fibroblasts and myocytes? Eur Heart J 31: 1771-1779, 2010.

44. Fujii H, Nishijima F, Goto S, Sugano M, Yamato H, Kitazawa R, Kitazawa S and Fukagawa M: Oral charcoal adsorbent (AST-120) prevents progression of cardiac damage in chronic kidney disease through suppression of oxidative stress. Nephrol Dial Transplant 24: 2089-2095, 2009.

45. Brito JS, Borges NA, Esgalhado M, Magliano DC, Soulage CO and Mafra D: Aryl hydrocarbon receptor activation in chronic kidney disease: Role of Uremic Toxins. Nephron 137: 1-7, 2017. 
46. Asai H, Hirata J and Watanabe-Akanuma M: Indoxyl glucuronide, a protein-bound uremic toxin, inhibits hypoxia-inducible factor-dependent erythropoietin expression through activation of aryl hydrocarbon receptor. Biochem Biophys Res Commun 504: 538-544, 2018.

47. Ito S, Osaka M, Edamatsu T, Itoh Y and Yoshida M: Crucial role of the aryl hydrocarbon receptor (AhR) in indoxyl sulfate-induced vascular inflammation. J Atheroscler Thromb 23: 960-975, 2016.

48. Barisione C, Ghigliotti G, Canepa M, Balbi M, Brunelli C and Ameri P: Indoxyl sulfate: A candidate target for the prevention and treatment of cardiovascular disease in chronic kidney disease. Curr Drug Targets 16: 366-372, 2015.

49. Esser $\mathrm{C}$ and Rannug A: The aryl hydrocarbon receptor in barrier organ physiology, immunology, and toxicology. Pharmacol Rev 67: 259-279, 2015.

50. Zhang $\mathrm{N}$ and Walker MK: Crosstalk between the aryl hydrocarbon receptor and hypoxia on the constitutive expression of cytochrome P4501A1 mRNA. Cardiovasc Toxicol 7: 282-290, 2007.

51. Ramezan A, Massy ZA, Meijers B, Evenepoel P, Vanholder R and Raj D: Role of the gut microbiome in uremia: A potential therapeutic target. Am J Kidney Dis 67: 483-498, 2016.

52. Dou L, Sallée M, Cerini C, Poitevin S, Gondouin B, Jourde-Chiche N, Fallague K, Brunet P, Calaf R, Dussol B, et al: The cardiovascular effect of the uremic solute indole- 3 acetic acid. J Am Soc Nephrol 26: 876-887, 2015.

53. Lund AK, Goens MB, Nuñez BA and Walker MK: Characterizing the role of endothelin-1 in the progression of cardiac hypertrophy in aryl hydrocarbon receptor (AhR) null mice. Toxicol Appl Pharmacol 212: 127-135, 2006.

54. Fernandez-Salguero PM, Ward JM, Sundberg JP and Gonzalez FJ: Lesions of aryl-hydrocarbon receptor-deficient mice. Vet Pathol 34: 605-614, 1997.
55. Wang Q, Chen J, Ko CI, Fan Y, Carreira V, Chen Y, Xia Y, Medvedovic M and Puga A: Disruption of aryl hydrocarbon receptor homeostatic levels during embryonic stem cell differentiation alters expression of homeobox transcription factors that control cardiomyogenesis. Environ Health Perspect 121: 1334-1343, 2013.

56. Zordoky BN and El-Kadi AO: Effect of cytochrome P450 polymorphism on arachidonic acid metabolism and their impact on cardiovascular diseases. Pharmacol Ther 125: 446-463, 2010.

57. Amara IE, Elshenawy OH, Abdelrady M and El-Kadi AO: Acute mercury toxicity modulates cytochrome $\mathrm{P} 450$, soluble epoxide hydrolase and their associated arachidonic acid metabolites in C57Bl/6 mouse heart. Toxicol Lett 226: 53-62, 2014.

58. Kaur-Knudsen D, Bojesen SE and Nordestgaard BG: Cytochrome P450 1B1 and 2C9 genotypes and risk of ischemic vascular disease, cancer, and chronic obstructive pulmonary disease. Curr Vasc Pharmacol 10: 512-520, 2012.

59. El-Sherbeni AA and El-Kadi AO: Alterations in cytochrome P450-derived arachidonic acid metabolism during pressure overload-induced cardiac hypertrophy. Biochem Pharmacol 87: 456-466, 2014

60. Malik KU, Jennings BL, Yaghini FA, Sahan-Firat S, Song CY, Estes AM and Fang XR: Contribution of cytochrome P450 1B1 to hypertension and associated pathophysiology: A novel target for antihypertensive agents. Prostaglandins Other Lipid Mediat 98: 69-74, 2012.

61. Ravarotto V, Simioni F, Pagnin E, Davis PA and Calò LA: Oxidative stress-chronic kidney disease-cardiovascular disease: A vicious circle. Life Sci 210: 125-131, 2018. 